\title{
Boundary layer flow and heat transfer on a moving plate in a copper-water nanofluid using Buongiorno model
}

\begin{abstract}
The study of the steady two dimensional boundary layer flow of a copper $(\mathrm{Cu})$-water nanofluid on a moving plate is investigated. The assumption is the plate moves in the same or opposite direction to the free stream. The nonlinear partial differential equations are transformed into nonlinear ordinary differential equations using a similarity variables, then a shooting technique is used to solved it numerically. The numerical results for skin friction coefficient, the local Nusselt number, the local Sherwood number as well as the velocity, temperature and concentration profiles are obtained. The effect of nanoparticle volume fraction, Brownian motion and thermophoresis parameters on heat transfer are examined. The results show that the local Nusselt number and the local Sherwood number increase with increasing in the Brownian motion parameter $\mathrm{Nb}$ and thermophoresis parameter $\mathrm{Nt}$.
\end{abstract}

Keyword: Boundary layer flow; Heat transfer; Copper-water nanofluid; Moving plate 